\section{RUTIRANJE VOZILA ZA SKUPLJANJE SMEĆA NA TERITORIJI GRADA TRSTENIKA}

dr Branko Davidović, inženjer saobraćaja

Visoka Tehnička Škola Strukovnih Studija Kragujevac, iwtbg@beotel.net

mr Zoran Šunjka, inženjer mašinstva

BAS Beograd, email: sunjkaz@bas.rs

Nemanja Stepanov, student postdiplomskih studija nemanja.stepanov@gmail.com

Stručni rad

Rezime: Cilj ovog rada je da na osnovu podataka dobijenih iz JKSP „Komstan“ Trstenik izvrši rutiranje vozila u skladu sa postojećim kapacitetima (brojem i nosivošću drumskih vozila - smećara u upotrebi) i na osnovu podataka o količini smeća po ulicama grada koje je potrebno pokupiti. Ovaj problem rutiranja vozila pripada problemima rutiranja vozila sa ograničenim kapacitetom. Klasa problema pripada grupi problema pod nazivom: Kineski poštar. Kako bi se dobila Ojlerova ruta, razvijen je jednostavan ali praktičan pristup za sparivanje čvorova transportne mreže Trstenika. Na kraju, prikazane su rute vozila. Eventualne benefite predloženog modela u odnosu na postojeće stanje nije moguće precizno odrediti zbog načina poslovanja privrednog društva, gde ne postoji ustaljeni plan ruta vozila jer se svakodnevno radi prema stanju na terenu.

Ključne reči: Kineski poštar, Ojlerova ruta, skupljanje smeća, rutiranje vozila, Trstenik.

\section{VEHICLE ROUTING FOR GARBAGE COLLECTION ON THE TERRITORY OF THE TRESTENIK CITY}

Branko Davidović, Ph.D. traffic engineering High Engineering School of Professional Studies Kragujevac, iwtbg@beotel.net

Zoran Šunjka, M.Sc. mechanical engineering BAS Belgrade, email: sunjkaz@bas.rs

Nemanja Stepanov, B.Sc. student of postgraduate studies, email: nemanja.stepanov@gmail.com

Professional paper

Abstract: The aim of this paper is to, based on the data obtained from JKSP "Komstan" Trstenik, carry out the routing of vehicles in accordance with the existing capacities (number and capacity of road vehicles in use) and based on data on the amount of garbage on the streets of the city to be picked up. This problem of routing the vehicle belongs to the problems of routing vehicles with limited capacity. The problem class belongs to a group of problems called: Chinese Postman. In order to get the Euler route, an easy but practical approach has been developed to match the nodes of the Trstenik transport network. Finally, the routes of the vehicles are shown. The possible benefits of the proposed model in relation to the existing situation cannot be precisely determined due to the way the company operates, where there is no established plan of the route of the vehicle, as it is done on a daily basis on the ground.

Keywords: Chinese postman problem, Euler routes, garbage collection, vehicle routing, Trstenik city.

\section{UVOD}

Lokalni ekološki akcioni plan (LEAP) opštine Trstenik je jedan od strateških opštinskih dokumenta, koji će zajedno sa drugim sličnim dokumentima usmeravati budući razvoj opštine i doprineti unapređenju uslova življenja. Ključnu ulogu u zaštiti životne sredine ima funkcija upravljanja komunalnim čvrstim otpadom i distribucija ispravne pijaće vode na teritoriji opštine Trstenik, što je povereno JKSP „Komstan“ Trstenik koje vrši sakupljanje, transport i odlaganje čvrstog komunalnog otpada na postojeću gradsku deponiju. Cilj ovog rada je da na osnovu podataka dobijenih iz JKSP „Komstan“ Trstenik izvrši optimizaciju rutiranja vozila za skupljanje smeća na teritoriji grada.

Klasičan problem rutiranja vozila (VRP) je jedan od najpopularnijih problema kombinatorne optimizacije, koji se u suštini svodi na problem trgovačkog putnika sa stohastičnim vremenom putovanja (TSPST).

Matematička formulacija koja je u širokoj upotrebi, zasnovana je na upotrebi binarnih promenljivih. Dalji razvoj i druge formulacije ovog problema mogu se naći u radovima (Laporte and Nobert 1987; Toth and Vigo 2002).

$U$ jednom realnom sistemu vozila nisu neograničenog kapaciteta, već poseduju neko ograničenje u količini robe u jedinici vremena koju treba da prevezu. U ovakvom sistemu pretpostavlja se da je poznata i potražnja za svakog od korisnika. Ovakav problem rutiranja se naziva: Problem rutiranja vozila sa ograničenim kapacitetom (CVRP/CVRPTW). Jednu od najpoznatijih heuristika za rešavanje ovog problema predložili su u svom radu Clarke and Wright (1964).

U okviru postavke problem rutiranja vozila sa vremenskim prozorima (VRPTW) svaki korisnik može biti posećen samo jedanput od strane jednog vozila. Svako vozilo ima isti kapacitet $q_{k}$, a svaki korisnik ima različite zahteve $m_{i}$. Kao i kod prethodnog problema, $q_{k}$ mora da bude veće od sume svih zahteva koje vozilo $k$ poseti tokom jedne rute. Drugim rečima, nijedno vozilo ne sme da bude pretovareno. Vremenski prozori znače da svaki korisnik ima najranije moguće i najkasnije moguće vreme kada vozilo mora da ga poseti. Ukoliko to nije 
moguće javlja se dodatno vreme čekanja, koje povećava troškove transporta.

Drugim rečima, vozilo ne sme da dođe do korisnika ranije ili kasnije od za to predviđenog vremena, inače će imati neko vreme kašnjenja. U definiciji ovog problema $u$ obzir se uzima i vreme opsluživanja prilikom posete svakog korisnika. Ovo vreme podrazumeva vreme utovara i istovara robe. Cilj je opslužiti sve korisnike uz što manje troškove prilikom transporta (Davidović 2016).

Metaheuristički pristupi su postigli najznačajnije rezultate prilikom rešavanja problema rutiranja vozila sa vremenskim prozorima. Metodu tabu pretraživanja (TS) primenili su sledeći autori (Taillard et al., 1997; Potvin et al., 2005). Primer rešavanja problema primenom simuliranog kaljenja (SA) možemo naći u radu Chiang and Russell, 1996. Genetske algoritme (GAs) pri rešavanju probleme koristili su autori u svojim radovima (Thangiah et al., 1991; Potvin i Bengio 1996). Optimizaciju kolonijom pčela (BCO), baziranu na grupnoj inteligenciji ovih insekata, primenili su u svom radu Nikolić i Teodorović, 2015.

Ukoliko se još bliže približimo nekom realnom sistemu, možemo pretpostaviti da neka od vozila ne moraju robu preuzimati samo u početnom mestu utovara, već je to moguće i u nekom od čvorova mreže, pa potom vršiti dalju distribuciju. U tom slučaju govorimo o postojanju "pick up" and "delivery" stanica, i rutiranju vozila u takvim uslovima. Dalje, postoje mnogi podproblemi koji problem rutiranja vozila približavaju realnim problemima.

Pretpostavimo da poštar raznosi poštu u jednom delu grada (područje). Poštar ima zadatak da obiđe sve ulice u području barem jednom. Obilazak svih ulica se može desiti na više načina. Postavlja se problem optimizacije, kojim putem treba poštar da raznosi pisma, a da bude što uspešniji. Drugim rečima, kojom rutom poštar treba da obiđe svoje područje na način da makar jednom obiđe svaku ulicu i da pri tome pređe što manje rastojanje i da se vrati na isto mesto odakle je i krenuo?

Problem kineskog poštara se može odnositi na razne delatnosti kao što su: određivanje ruta vozila za pranje ulica, sakupljanje otpada, ili drugih komunalnih službi poput zimskih službi za čišćenje snega, prevoz dece, učenika itd... Problemom kineskog poštara bavili su se sledeći autori (Edmonds and Johnson 1973, Eiselt et al.1995, Nobert and Picard 1996, Gutin et al. 2017, Dreifus et al. 2017).

Prilikom odnošenja smeća iz jedne urbane sredine realna pretpostavka je, da se u svakoj ulici poznata prosečna količina smeća koju treba odneti. Potom, sledeća pretpostavka je da su poznate i dužine grana koje treba opslužiti.

Iz navedenih pretpostavki može se zaključiti da je problem rutiranja takav da treba proći svakom granom mreže najmanje jedanput, da se odnese poznata količina smeća sa vozilima ograničenog kapaciteta, a da se pritom pređe najkraći mogući put.

Algoritmi za rešavanje problema kineskog poštara, koji spada u grupu opštih problema, pogodni su za rešavanje konkretnog problema rutiranja vozila za skupljanje smeća.

\section{PROBLEM KINESKOG POŠTARA I OJLEROV GRAF}

Povezani Ojlerov graf je onaj kod koga su svi čvorovi parnog stepena. Stepen čvora je određen brojem grana koji ga povezuju sa drugim čvorovima grafa.

Povezani graf je graf u kom za svaka dva čvora na grafu postoji put koji iz jednog čvora vodi u drugi.

Ojlerova ruta je ruta koja prolazi svakom granom grafa $G$, što znači da sadrži svaku granu tačno jednom. Ojlerova ruta je zatvorena. Graf $G$ je Ojlerov graf ako na njemu postoji Ojlerova ruta.

Za neusmereni graf $G=(N, A)$ gde su dužine grana $d(i, j)>0,(i, j \in A)$ problem kineskog poštara se može formulisati na sledeći način (Davidović 2016):

$$
\min \sum_{\forall(i, j) \in A} s_{i j} \cdot d_{i j}
$$

gde je $s_{i j}$-broj prolazaka granom.

Ako se na Ojlerovom grafu rešava problem kineskog poštara, može se zaključiti da je rešenje trivijalno jer predstavljaju Ojlerovu rutu. Suma dužina grana grafa je dužina puta koju poštar treba da pređe jer će posetiti sve grane samo jednom i vratiti se $u$ početni čvor grafa.

Ako graf nije Ojlerov tada poštar treba da posetiti neke od grana više puta. Problem optimizacije se sastoji u određivanju koje grane poštar mora da poseti više puta, a da svoju rutu završi uz minimalnu dužinu pređenog puta.

Da bi se pronašla ruta poštara sa minimalnom ukupnom dužinom potreban je algoritam koji će za slučaj da graf nije Ojlerov umetnuti, na najbolji mogući način, veštačke grane. Koraci potrebni za rešavanje problema kineskog poštara na neusmerenom grafu prikazani su u sledećem algoritmu: 
Algoritam rešavanja problema kineskog poštara:

1) Prebrojati sve čvorove neparnog stepena,

2) Prebrojati sva moguća povezivanja parova čvorova neparnog stepena,

3) Pronaći povezivanje čvorova sa najmanjom težinom veštačkih grana,

4) $\mathrm{Na}$ originalni graf dodati pronađeno povezivanje sa minimalnom težinom,

5) Ukupna težina rute je zbir težina svih grana grafa.

\section{STUDIJA SLUČAJA GRADA TRSTENIKA}

Mreža sa slike 1. pokazuje ulice kojima će se kretati vozila za skupljanje smeća, uprošćena je i prikazana zajedno sa rastojanjima između čvorovima mreže.

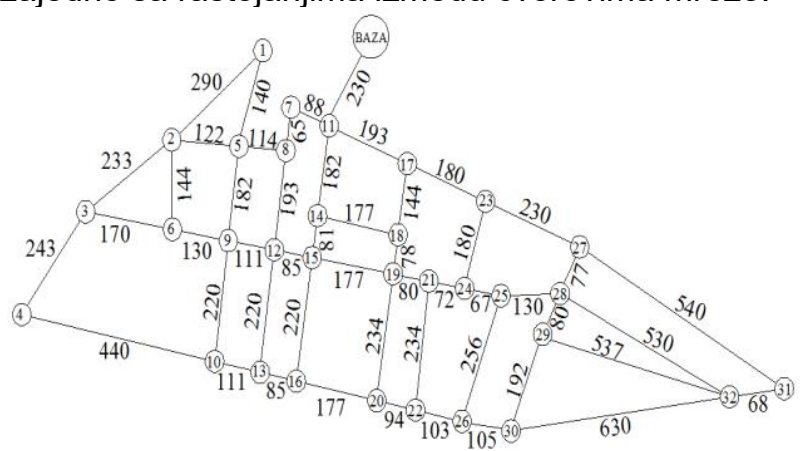

Slika 1. Transportna mreža grada Trstenika

Vrednosti stepena čvorova date su u tabeli 1.

Tabela 1. Stepeni čvorova transportne mreže

\begin{tabular}{|c|c|c|c|c|c|c|c|}
\hline Čvor & $\begin{array}{c}\text { Stepen } \\
\text { čvora }\end{array}$ & Čvor & $\begin{array}{c}\text { Stepen } \\
\text { čvora }\end{array}$ & Čvor & $\begin{array}{c}\text { Stepen } \\
\text { čvora }\end{array}$ & Čvor & $\begin{array}{c}\text { Stepen } \\
\text { čvora }\end{array}$ \\
\hline 1 & 2 & 9 & 4 & 17 & 3 & 25 & 3 \\
\hline 2 & 4 & 10 & 3 & 18 & 3 & 26 & 3 \\
\hline 3 & 3 & 11 & 4 & 19 & 4 & 27 & 3 \\
\hline 4 & 2 & 12 & 4 & 20 & 3 & 28 & 4 \\
\hline 5 & 4 & 13 & 3 & 21 & 3 & 29 & 3 \\
\hline 6 & 3 & 14 & 3 & 22 & 3 & 30 & 3 \\
\hline 7 & 2 & 15 & 4 & 23 & 3 & 31 & 2 \\
\hline 8 & 3 & 16 & 3 & 24 & 3 & 32 & 4 \\
\hline
\end{tabular}

Kako se i baza može smatrati čvorom, zaključak je da postoji 20 čvorova sa neparnim stepenom, koji se mogu spariti na 654729075 načina. Zbog veoma velikog broja mogućih sparivanja primenjuje se jednostavan algoritam sparivanja čvorova sa neparnim stepenom:

Korak 1. Početi od prvog čvora mreže, koji ima neparni stepen, i spariti ga sa sledećim najbližim susednim čvorom, koji ima neparni stepen. Drugim rečima, spajaju se susedni čvorovi koji su najbliži jedan drugom, počevši od prvog čvora mreže sa neparnim stepenom.
Korak 2. Ponavljati korak 1 sve dok postoje neparni čvorovi na mreži. Korak 1. možda neće dati optimalna sparivanja, ali će dati dovoljno dobra rešenja za prihvatljivo vreme i na jednostavan način.

Dodavanje grana, u obliku luka, prikazano je na slici 2. Ovim se postiže transportna mreža koja ima Ojlerovu rutu i može se krenuti u projektovanje ruta vozila za skupljanje smeća. Dužine grana date su u metrima.

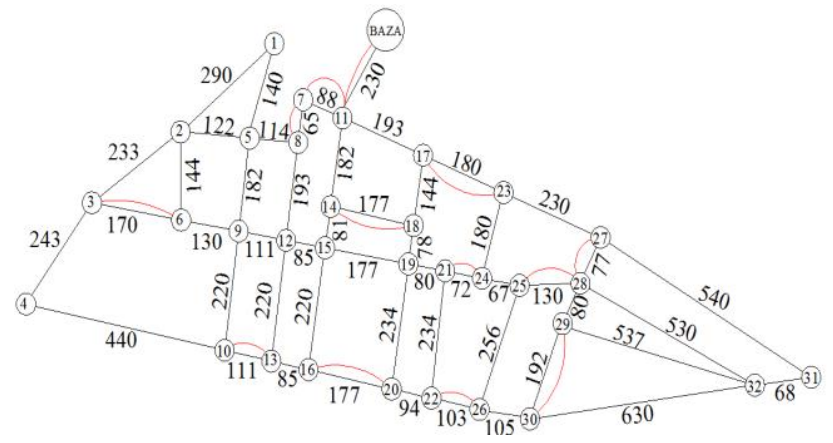

Slika 2. Transportna mreža grada Trstenika koja ima Ojlerovu rutu

Prema podacima dobijenim iz JKP "KOMSTAN" ovo preduzeće poseduje sledeće kamione za skupljanje smeća sa sledećim nosivostima:

1) Auto-Smećar FAP 26-28, nosivosti 10,6 t,

2) Auto-Smećar FAP 19-21, nosivosti $8,6 \mathrm{t}$,

3) Auto-Smećar SKANIA-VABIS G-820, nosivosti 4,8 t,

4) Auto-Smećar FAP 12-13, nosivosti $4,1 \mathrm{t}$,

5) Auto-Smećar FAP 14-18, nosivosti 3,5 t.

Količina smeća, data u tonama, koju je potrebno pokupiti data je na narednoj slici 3. Ovi podaci su usvojeni u skladu sa prosečnim količinama smeća koje je potrebno pokupiti na granama mreže.

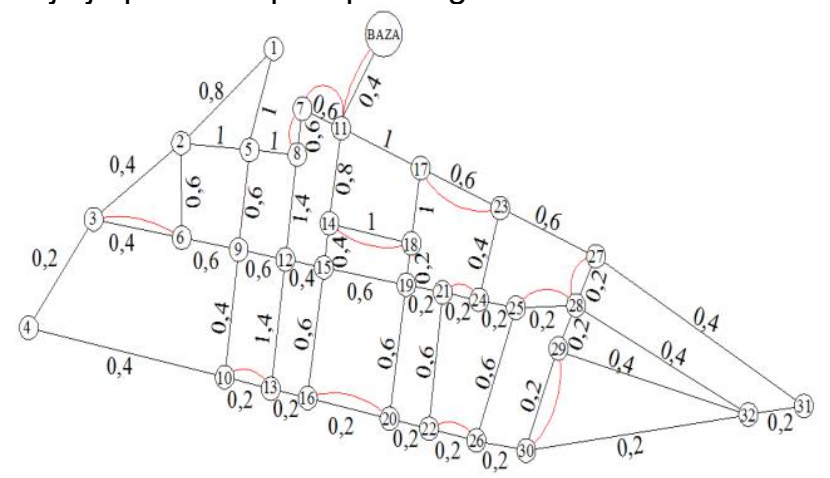

Slika 3. Količina smeća koju je potrebno pokupiti po granama transportne mreže

Ukupna količina smeća koju je potrebno pokupiti na transportnoj mreži iznosi $26 \mathrm{t}$. Sa obzirom da preduzeće poseduje dovoljno kapaciteta u vidu smećara za skupljanje otpada koristiće se 4 od 5 raspoloživih vozila. Ovim se postiže da praktično nema praznih vožnji prilikom transporta. 
Raspodelom vozila na radne zadatke, dobijene su sledeće rute:

\section{Ruta 1: Baza-11-7-8-5-1-2-3-4-10-9-6-3-6-2-5-9-12 18-7-11-Baza}

Rutom 1 se kreće vozilo Auto-Smećar FAP 26-28, nosivosti 10,6 t. Na ovoj ruti ukupno se pokupi 10,6 t smeća, pa je ovo vozilo iskorišćeno $100 \%$. Na ovoj ruti vozilo ne kupi smeće na grani Baza-11.

Ruta 2: Baza-11-14-15-12-13-10-13-16-15-19-1814-18-17-11-Baza

Rutom 2 se kreće vozilo Auto-Smećar FAP 19-21, nosivosti 8,6 t. Na ovoj ruti ukupno se pokupi 8,2 t smeća, pa je stepen iskorišćenosti ovog vozila $95 \%$. $\mathrm{Na}$ ovoj ruti vozilo kupi smeće na svakoj grani transportne mreže, uključujući i granu Baza-11.

Ruta 3: Baza-11-17-23-24-21-19-20-16-20-22-2124-25-28-27-23-17-11-Baza

Rutom 3 se kreće vozilo Auto-Smećar SKANIAVABIS G-820, nosivosti 4,8 t. Na ovoj ruti se pokupi 4,2 t smeća, pa je stepen iskorišćenja ovog vozila $87 \%$. Na ovoj ruti vozilo ne kupi smeće na granama Baza-11-17.

Ruta 4: Baza-11-17-23-27-31-32-28-29-32-30-2930-26-22-26-25-28-27-23-17-11-Baza

Rutom 4 se kreće vozilo Auto-Smećar FAP 14-18, nosivosti 3,5 t. Na ovoj ruti se pokupi 3 t smeća, pa je stepen iskorišćenja ovog vozila $86 \%$. Na ovoj ruti vozilo ne kupi smeće na grani Baza-11-17-23-27.

\section{ZAKLJUČAK}

U radu je prikazan heuristički algoritam za sparivanje čvorova u cilju dobijanja Ojlerove rute. Sa obzirom na veliki broj mogućih sparivanja čvorova predložen je jednostavan, ali praktičan pristup. Na realnom primeru ulične mreže Trstenika pokazana je njegova primena i generisane su rute za vozila za skupljanje smeća.

JKSP „Komstan“ Trstenik nema ustaljeni način dodeljivanja vozila na rute, već se taj posao obavlja u skladu sa trenutnom situacijom i raspoloživim brojem smećara. Sa obzirom na ovu činjenicu nije moguće uporedi ovaj način rutiranja sa postojećim i dokazati eventualne benefite. Potrebno je, $u$ budućnosti ispitati kolike su zapravo koristi jednog ovakvog pristupa za poslovanje privrednog društva i eventualne uštede.

Ovaj pristup, ne garantuje optimalno rešenje problema, ali daje dovoljno dobro rešenje uz jedan jednostavan ali primenljiv algoritam. Pored ovoga, ukoliko dođe do nekih promena ulaznih parametara (nabavka novih smećara, proširenje mreže i sl.) potrebno je ponoviti ceo opisani postupak.
U budućim istraživanjima mogao bi se razviti nov algoritam, baziran na metahurističkim metodama (SA i/ili GAs algoritmi i sl.) za rešavanje problema kineskog poštrara, koji bi povećao složenost ali možda uspeo i da se približi optimalnom rešenju postavljenog problema.

\section{Literatura}

[1] Chiang, W. C., Russell, R., (1996). "Simulated annealing meta-heuristics for the vehicle routing problem with time windows". Annals of Operations Research, 93(1), 3-27.

[2] Clarke, G., Wright, J.W., (1964). "Scheduling of vehicles from a central depot to a number of delivery points". Operations Research, 12, 568-581.

[3] Davidović, B., (2016). "Modeliranje i odlučivanje u logističkim procesima". AGM knjiga, Beograd.

[4] Dreifus, G., et al., (2017). "Path Optimization Along Lattices in Additive Manufacturing Using the Chinese Postman Problem". 3D Printing and Additive Manufacturing, 4(2), 98104.

[5] Edmonds, J., Johnson, E.L., (1973). "Matching, Euler tours and the Chinese postman". Mathematical programming, 5(1), 88-124.

[6] Eiselt, H.A., et al., (1995). "Arc routing problems, part I: The Chinese postman problem". Operations Research, 43(2), 231-242.

[7] Gutin, G., et al., (2017). "Chinese Postman Problem on edge-colored multigraphs". Discrete Applied Mathematics, 217, 196-202.

[8] Laporte, G., Nobert, Y., (1987). "Exact algorithms for the vehicle routing problem". Annals of Discrete Mathematics, 31, 147-184.

[9] Nikolić, M. and Teodorović, D., (2015). "The vehicle rerouting problem with time windows and split delivery". $2^{\text {nd }}$ Logistics International Conference, Belgrade, maj 2015, pp. 55-60.

[10]Nobert, Y. and Picard, J.C., (1996). "An optimal algorithm for the mixed Chinese postman problem". Networks, 27(2), 95-108.

[11]Potvin, J.Y. and Bengio, S., (1996). "The vehicle routing problem with time windows part II: Genetic Search". INFORMS Journal on Computing, 8(2), 165-172.

[12]Potvin, J.Y. et al., (2005). "The vehicle routing problem with time windows part I: Tabu search". INFORMS Journal on Computing, 8 (2), 158-164.

[13]Taillard, E. et al., (1997). "A Tabu search heuristic for the vehicle routing problem with soft time windows". Transportation Science 31(2), 170-186.

[14]Thangiah, S. R. et al., (1991). "GIDEON: A Genetic Algorithm System for routing problem with time windows". $7^{\text {nd }}$ IEEE Conference on Artificial Intelligence Applications, Miami Beach, February 1991, pp. 322-328.

[15]Toth, P. and Vigo, D., (2002). "The Vehicle Routing Problem". Philadelphia: Society for Industrial and Applied Mathematics. 